\title{
Impact of Climate Change on Livestock Returns and Rangeland Ecosystem Sustainability in the Southwest
}

\author{
Gregory L. Torell, and Katherine D. Lee
}

\begin{abstract}
Climate change will increase variability in temperature and precipitation on rangelands, impacting ecosystem services including livestock grazing. Facing uncertainty about future climate, managers must know if current practices will maintain rangeland sustainability. Herein, the future density of an invasive species, broom snakeweed, is estimated using a long-term ecological dataset and climate projections. We find that livestock stocking rates determined using a current method result in lower forage production, allowable stocking rate, and grazing value than an economically efficient stocking rate. Results indicate that using ecology and adaptive methods in management are critical to the sustainability of rangelands.
\end{abstract}

Key Words: climate change, invasive species, livestock stocking management, rangeland economics, rangeland ecosystem services, uncertainty

Ecosystems characterized as rangelands are arid or semi-arid landscapes dominated by grasses, forbs, and shrubs, and they comprise 30 percent of the land area in the United States (Havstad et al. 2009). Rangelands provide habitat and forage for livestock producers, making them an integral part of the cultural and economic identity of the American West (Costanza et al. 1997; Havstad et al. 2007). Determining the ecologically and economically sustainable number of livestock to graze on rangelands is usually based on prescriptive livestock stocking rules. Take half leave half or 50 percent utilization is a commonly used stocking rule, where the stocking rate - the number of livestock permitted to graze on a piece of land for a given period of time - is set to leave roughly half the standing grazeable forage at the end of the grazing season. The 50 percent utilization rule has proven effective in maintaining rangeland sustainability and ranch profitability across numerous rangeland sites and conditions, and it has the benefit of being simple to understand and implement.

Annual stocking rates are set before annual temperature, precipitation, and forage production are realized. As a result, rangeland managers must predict the available biomass of grazeable forage as a function of the observed state

Gregory L. Torell, Texas A\&M AgriLife Research at El Paso, and Katherine D. Lee, University of Idaho, Department of Agricultural Economics and Rural Sociology. Correspondence: Gregory L. Torell - Texas A\&M AgriLife Research at El Paso - Email: Gregory.Torell@ag.tamu.edu

Agricultural and Resource Economics Review 47/2 (August 2018) 336-356

(C) The Author(s) 2018. This is an Open Access article, distributed under the terms of the Creative

Commons Attribution licence (http://creativecommons.org/licenses/by/4.0/), which permits unrestricted re-use, distribution, and reproduction in any medium, provided the original work is 
of the range, including climate (temperature and precipitation), standing forage, and density of weed species. While choosing a "heavy" stocking rate and therefore high grazing pressure can negatively affect future range condition, exogenous factors such as drought or spread of noxious weeds are also significant factors in range condition.

In Southwestern United States rangelands, summer precipitation is the most critical factor in forage biomass production, specifically for blue grama (Bouteloua gracilis) (McDaniel, Torell, and Bain 1993). Blue grama production is significantly reduced by the presence of broom snakeweed (Gutierrezia sarothrae), an undesirable woody shrub that is toxic to livestock (Ueckert 1979; McDaniel 1984). Climate change projections indicate that Southwestern rangelands will face greater seasonal variability in precipitation and increased temperatures, implying potentially longer and more severe droughts (Pachauri and Reisinger 2007; Briske et al. 2015). These conditions are anticipated to alter plant communities and rangeland ecosystems directly through species die-offs and indirectly by, for example, more frequent fire events. How projected changes to temperature and precipitation will specifically blue grama productivity directly, and indirectly through broom snakeweed proliferation, is unknown. Another question that remains is if stocking rules such as 50 percent utilization will be robust, ecologically and economically, given the impacts of climate change on forage and other primary producers in rangelands. Assessing the effects of climate change on primary production and the outcomes of continued use of rangeland management rules such as 50 percent utilization ex ante is essential for rangeland sustainability and formulating adaptation to climate change.

There have been numerous general calls for the scientific community to provide guidance for decision makers in the face of changing climate (Moss et al. 2010; Nicol et al. 2015, and others). In rangeland ecosystems, the existing economics literature has addressed how variability in temperature and precipitation affect optimal stocking rates in rangelands. Torell, Lyon, and Godfrey (1991) use an average of annual forage production in an analysis of the significance of time horizons in stocking rate decisions but assume that stochastic weather shocks have a mean of zero. Subsequent analyses have found that setting stocking rates using average annual forage productivity will result in overgrazing and rangeland degradation during prolonged years of drought, which is a likely outcome of future climate. More recent analyses use optimal control models in combination with state-andtransition frameworks to model optimal response to uncertainty in environmental conditions. Ritten et al. (2010) incorporate stochastic annual temperature and precipitation into a dynamic framework to assess their effect on optimal stocking rates and range conditions. Further, recent publications have examined the effects of variable inter-year weather and climate change on rangeland production and profitability (Baker et al. 1993; Reeves et al. 2013; Kachergis et al. 2014; Kobayashi, Rollins, and Taylor 2014). While the existing literature addresses the significance of climate 
variability on annual forage production and therefore optimal stocking rates, range managers continue to use rules of thumb in stocking-rate determination. The effect of continued use of rules of thumb, as opposed to an adaptive framework, on forage and undesirable species biomass is unknown.

The objective of this work is to determine the impact of climate change on future rangeland forage production and the effect of stocking rules on rangeland and ranch sustainability. We develop a state-and-transition model to simulate annual forage (blue grama) and nonforage (broom snakeweed) productivity for given rangeland conditions. The model is parameterized by estimating probabilities of transition in forage and broom snakeweed biomass using a 35-year record of environmental and ecological data from three rangeland sites in New Mexico. Using the estimated coefficients on plant productivity, we simulate how two atmospheric greenhouse gas concentration projections affect production biomass of blue grama and broom snakeweed. Finally, we compare rangeland forage production (sustainability) and ranch profitability outcomes under the 50 percent utilization and profit-maximizing stocking rules for both greenhouse gas concentration projections.

This analysis is designed to inform how rangeland management rules of thumb perform under climate change scenarios. Our results demonstrate the impacts of failing to consider the effect of exogenous factors on future states of the range. In the following section we detail the bioeconomic modeling framework, in the third section we present the simulation results, and the final section discusses implications of this work.

\section{Model}

We use temperature and precipitation projections and a state-and-transition model framework to simulate annual forage and weed production using two different climate scenarios. The state-and-transition framework is then used by the representative rangeland manager (stocker cattle operation) in Northeast New Mexico to predict annual forage production and choose a stocking rate. The availability of forage and chosen livestock stocking rate together determine the value of the rangeland for livestock production. To test the assumption that the economic outcome of the 50 percent utilization rule does not significantly differ from a profit-maximizing stocking rule, we compare the value generated using the 50 percent utilization and profitmaximizing stocking rules under two climate scenarios. The two scenarios used are a baseline, where atmospheric greenhouse gas concentrations are assumed not to change from current (1950-2015) levels, and the Representative Concentration Pathway 8.5 (RCP 8.5) scenario, which assumes greenhouse gas concentrations continue to rise through the year 2100. A flowchart of the full simulation and inputs is shown in Figure 1. In the figure, data that are determined from draws from stochastic distributions are denoted by oval shapes, computed values denoted by rectangles, and the stocking rate policy is in a parallelogram. This figure shows that broom 


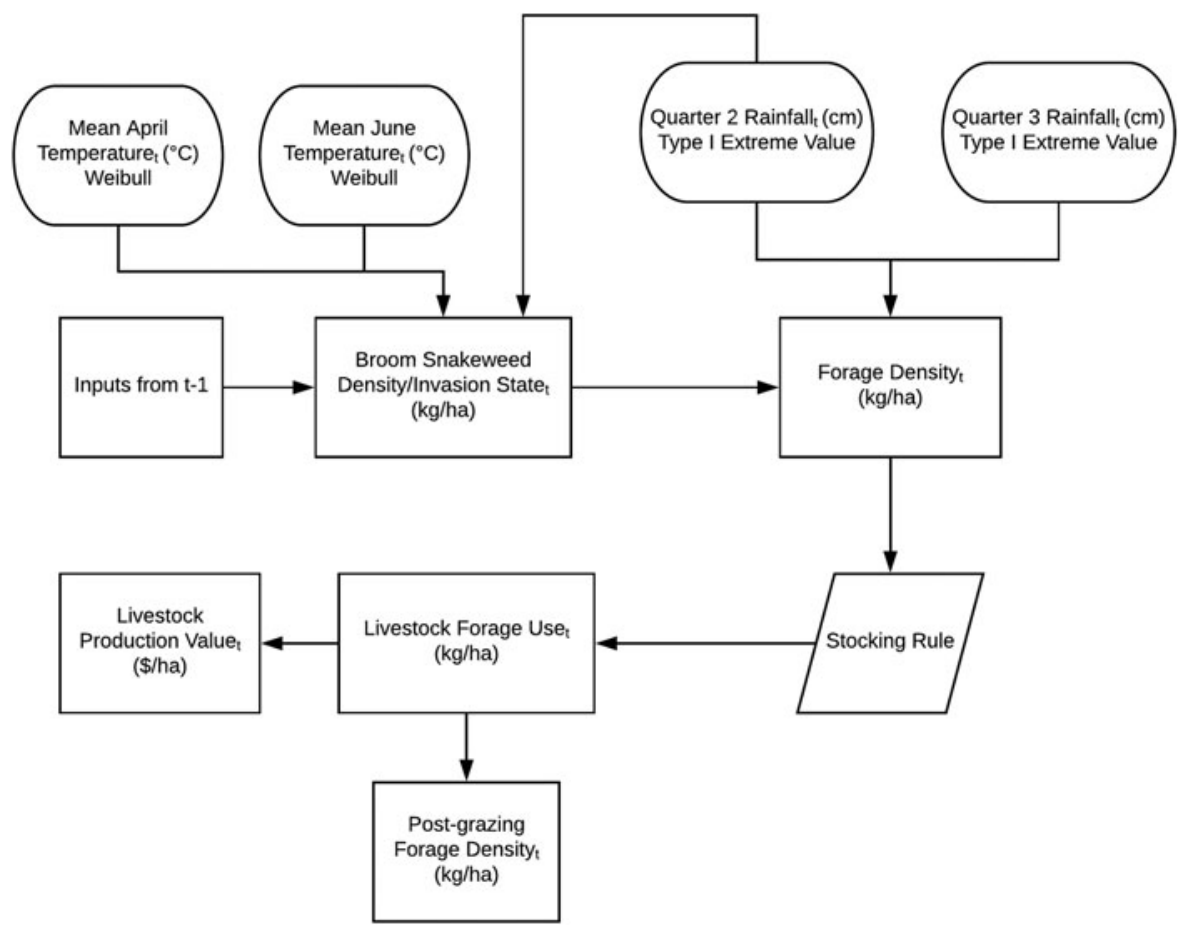

Figure 1. Flowchart of the modeling framework used in the analysis. Data that are determined from draws from stochastic distributions are denoted by ovals, computed values denoted by rectangles, and stocking rate policy is in a parallelogram.

snakeweed density from the previous period, carry-over forage, and contemporaneous weather define the broom snakeweed density in the current period. Current broom snakeweed density and weather define the current stock of forage. The stocking rule is used to determine the stocking rate, given the current stock of forage, which determines livestock forage use, net returns from grazing, and the remaining stock of forage, which will be carry-over forage for the next grazing season.

We use a $2 \times 2$ factorial design; the factors used in this paper are projected climate conditions, the baseline and RCP 8.5, and two stocking rules, 50 percent utilization and profit maximizing.

\section{The Ecological State-and-Transition Model}

To determine how forage and weed biomass are affected by climate scenarios, we use a state-and-transition framework that is incorporated into a Monte Carlo simulation. State-and-transition models are nonequilibrium ecological models 
that describe the possible composition and densities of vegetation on a site, and the probability that a site will transition away from its current vegetation composition. The Monte Carlo simulation takes random draws from probability distributions for four environmental variables: precipitation in quarter two (April - June), precipitation in quarter three (July - September), average temperature in April, and average temperature in June. In all, 10,000 draws are taken for each: year, starting state of invasion on the range, and for each level of the factors, giving 3.2 million observations in total. Annual forage production is estimated for each of these draws using a logistic growth function. Simultaneously, environmental variables also define the probabilities of a change in weed site density, based on the estimated ordered logit function described above. From the estimated amount of forage available for that given year and level of the factors, the rangeland manager determines the stocking rate for that year. In the results section, the results are presented as the distribution of outcomes from all of the draws taken, across years and by level of the factors.

\section{Stocking Rate Determination}

50 percent utilization stocking rate: The 50 percent utilization rule sets the stocking rate by determining how many animals can graze a unit area of land for a given period, leaving 50 percent of available forage. This stocking rule has been found to be as effective as more sophisticated stocking rules (Torell, Lyon, and Godfrey 1991; Quaas et al. 2007). For this reason, we compare the 50 percent utilization outcomes with a profit-maximizing stocking rule. The quantity of standing forage after the previous year's grazing season and the current year's annual temperature and precipitation are used to determine an expectation of current year forage biomass. Assuming daily requirements for stockers to be $12 \mathrm{~kg} /$ day/head and a fixed grazing season, May 1 through October 1 (153 days), 50 percent utilization for a 1,000 hectare site would be set so the total forage consumption at the end of the season would be equal to $500 \mathrm{~kg} / \mathrm{ha}$, or $0.27 \mathrm{head} / \mathrm{ha}$,

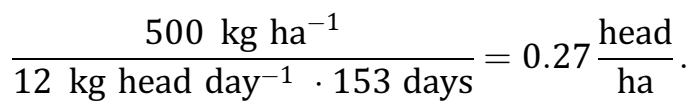

The manager is assumed to be a myopic agent and does not consider range conditions observed in the previous year, nor do they consider the impact that the current year's grazing will have on future range conditions, beyond the conservative approach that the grazing rule implies.

Profit-maximizing stocking rate: A profit-maximizing stocking rate requires maximizing operation profit by choosing the number of cattle to stock, given exogenous beef prices and production costs. The chosen stocking rate factors into the weight gain of livestock and eventually the weight-based sale price 
of animals for sale at the end of the grazing season. Aggregate livestock growth increases as the stocking rate increases because more animals are added to the operation, but because rangeland forage is finite in supply, adding additional animals creates competition for forage and lower individual growth. When cattle graze on open range, the stocking rate is the only decision variable (other than supplementary feeding midseason, which is ignored in this paper) in a livestock production function.

The producer's annual profit function is maximized in a static framework, by choosing a stocking rate, $S R$, at the beginning of each growing season. We assume the producer is just maximizing profits for the single year. Revenue is a function of the per-kilogram sale price of cattle $P_{s}$ and the herd weight (weight of individual $\times$ number of individuals), $f(S R)$, where $S R$ is the stocking rate. Variable production costs include the per weight purchase cost, $P_{p}$, multiplied by the purchase weight, $W_{p}$, and variable production costs, $c$. Fixed costs are denoted as $b$. The livestock enterprise profit function is

$$
\pi=P_{s} f(S R)-S R \cdot\left(P_{p} W_{p}+c\right)-b .
$$

At the optimal choice of stocking rate, the marginal benefit of adding another animal to the herd is equal to the costs of adding that animal, which include production costs and the reduction in overall herd performance.

The herd sale weight is a function of the stocking rate multiplied by average daily gains (kg/day), $A D G$, and the length of the grazing season, $v$,

$$
f(S R)=S R \cdot A D G \cdot v .
$$

We follow a common assumption in the literature (McCarthy et al. 2001) and assume that average daily gains are a linear function of grazing pressure (defined below),

$$
A D G=\beta_{0}+\beta_{1} \cdot G P
$$

where $\beta_{0}$ and $\beta_{1}$ are the intercept and slope of the average daily gain equation, respectively. Hart et al. (1988) find these parameters to be 1.13 and -0.00625 for grazing pressures above 29 steer-days/tonne of forage. Grazing pressure GP is defined as the steer-days per unit of forage production,

$$
G P=(S R \cdot v) / H,
$$

where $H$ is the forage production output from the model in $\mathrm{kg} / \mathrm{ha}$. Therefore, the aggregate weight of animals raised is expressed as

$$
f(S R)=\beta_{0} \cdot v \cdot S R+\frac{\beta_{1} v^{2}}{H} \cdot S R^{2} .
$$


Using a profit-maximizing stocking rule, the grazing manager will set the stocking rate such that the value of the marginal product from adding an additional animal to the herd is equal to the marginal factor cost. This relationship can be rearranged to express the optimal stocking rate as a function of the forage, length of the grazing season, and the other parameters in the model,

$$
S R=\frac{H\left(P_{p} W_{p}+c-\beta_{0} v\right)}{2 \beta_{1} v^{2}} .
$$

From (7), all else equal, a larger volume of available forage $H$ results in an increase in the optimal stocking rate. In addition, all else equal, increasing the length of the grazing season, $v$, will reduce the optimal stocking rate. Similar to the assumptions made for a manager following the 50 percent utilization rule, the rangeland manager that follows the profit-maximizing grazing rule is assumed to make the determination of the standing stock of forage at the beginning of the grazing season and use this information to determine stocking rates. While a more sophisticated agent could consider the impact that current stocking rates have on future range conditions and mid-season production adjustments, this possibility is left as future work.

We perform Monte Carlo simulations by taking 10,000 draws for each climate scenario, stocking rule, and initial level of broom snakeweed invasion, from the temperature and precipitation distributions of the climate scenarios to simulate forage and weed production over the time horizon. To compare the ecological and economic outcomes of the two stocking rules, we assume a 20-year horizon for the livestock enterprise and calculate the net present value per hectare over that period. Net present values are determined from the sum of the discounted simulated net returns per hectare over 20 years in each simulation, with an assumed 4 percent discount rate, reflecting current operating loan rates. The distribution of net present values from each Monte Carlo simulation creates a basis of economic comparison between the greenhouse gas concentration scenarios and the stocking rules, while the distribution of forage and broom snakeweed outcomes creates a basis of ecological comparison.

\section{Study System and Data}

We use data from the Prairie region of central New Mexico's Highland Major Land Resource Area (MLRA), designated by the Natural Resources Conservation Service (NRCS). On these sites, the vegetative mosaic consists primarily of broom snakeweed and blue grama. Blue grama and broom snakeweed density, temperature, and precipitation were collected between 1979 and 2014. Further detail on the study site and data collection can be found in (McDaniel 1984) and Torell et al. (2018). 


\section{Climate Data}

The HadGEM2-CC365 and CCSM4 global climate change models for MLRA were used for temperature and precipitation projections (Gent et al. 2011). Multivariate Adaptive Constructed Analogs (MACA) statistical method was used to downscale global climate model projections to a spatial resolution that matched the scale of the ecological data used in the analysis. MACA enabled daily ensemble weather projections of various future emissions scenarios for the study region ${ }^{1}$.

Two greenhouse gas atmospheric concentration scenarios were used to determine temperature and precipitation projections, a historical baseline and the RCP 8.5 scenario. The baseline data projects climate trends assuming no increase or decrease current in greenhouse gas emissions from 19502015 conditions. Under RCP 8.5, greenhouse gas concentrations are assumed to continue to rise through the year 2100 , and the scenario is named after the assumed radiative forcing values in the year 2100 relative to 1850 values $\left(+8.5 \mathrm{~W} / \mathrm{m}^{\wedge} 2\right)^{2}$. Minimum, maximum, and average daily temperature and precipitation for the baseline and RCP 8.5 projections were collected for years 2050 to 2099. Table 1 shows the average precipitation and temperature and the associated standard deviation for both projections.

The distributions used for the stochastic weather draws within the Monte Carlo simulations are based on HadGEM2-CC365 and CCSM4 data that has been downscaled to the study region. The distributions from which draws are taken are fitted to the observed downscaled data using the fitting routines provided within @RISK 7.5 simulation software. The probability density functions used in fitting these distributions and the parameterizations used for each fitted distribution are provided in Table 1.

\section{Ecological Data}

We use vegetation biomass surveys and weather data from the field sites and the framework detailed in (Torell et al. 2018) to estimate the effects of temperature and precipitation on forage and weed biomass in the state-andtransition model. Broom snakeweed biomass density is placed into four categories (none, low, medium, and high) and an ordered logit model estimates the probability of change density. The variables included in the regression are the state of snakeweed invasion in the previous period, snakeweed density in the previous period, grazeable forage production in the previous period, average daily temperature in April, average daily

\footnotetext{
1 MACA Statistically Downscaled Climate Data from CIMP5, http://maca.northwestknowledge. net

2 Radiative forcing, notated as Watts per square meter, is the difference in energy that enters the atmosphere and the amount that is returned to space.
} 
Table 1. Distributions Used for Exogenous Weather Draws in the Monte Carlo Simulations of Primary Productivity.

\begin{tabular}{|c|c|c|c|}
\hline $\begin{array}{l}\text { Climate } \\
\text { Scenario }\end{array}$ & Weather Variable & Distribution & Parameters \\
\hline \multirow[t]{4}{*}{ Baseline } & Qtr 2 Rainfall (cm) & Gumbel & $\begin{array}{l}\text { Location: } 14.4013 \text { Scale: } 7.4753 \\
\quad \text { Mean: } 18.737 \text { SD: } 9.572\end{array}$ \\
\hline & Qtr 3 Rainfall (cm) & Gumbel & $\begin{array}{l}\text { Location: } 7.3791 \text { Scale: } 4.1043 \\
\text { Mean: } 9.773 \text { SD: } 5.246\end{array}$ \\
\hline & April Temperature $\left({ }^{\circ} \mathrm{C}\right)$ & Weibull & $\begin{array}{l}\alpha: 2.2685 \beta: 3.4969 \text { Mean: } \\
15.3448 \text { SD: } 1.4460\end{array}$ \\
\hline & June Temperature $\left({ }^{\circ} \mathrm{C}\right)$ & Weibull & $\begin{array}{l}\alpha: 5.8339 \beta: 6.7251 \text { Mean: } 25.111 \\
\text { SD: } 1.2387\end{array}$ \\
\hline \multirow[t]{4}{*}{ RCP 8.5} & Qtr 2 Rainfall (cm) & Gumbel & $\begin{array}{l}\text { Location: } 7.8052 \text { Scale: } 4.0337 \\
\text { Mean: } 10.144 \text { SD: } 5.166\end{array}$ \\
\hline & Qtr 3 Rainfall (cm) & Gumbel & $\begin{array}{l}\text { Location: } 3.1171 \text { Scale: } 2.2766 \\
\text { Mean: } 4.529 \text { SD: } 2.864\end{array}$ \\
\hline & April Temperature $\left({ }^{\circ} \mathrm{C}\right)$ & Weibull & $\begin{array}{l}\alpha: 5.8250 \beta: 8.5503 \text { Mean: } 20.778 \\
\quad \text { SD: } 1.577\end{array}$ \\
\hline & June Temperature $\left({ }^{\circ} \mathrm{C}\right)$ & Weibull & $\begin{array}{l}\alpha: 3.4816 \beta: 4.0857 \text { Mean: } \\
32.9867 \text { SD: } 1.1685\end{array}$ \\
\hline
\end{tabular}

temperature in June, and total precipitation in quarter two (April-June). Summary statistics for temperature and precipitation under the climate scenarios are summarized in Table 2. The estimated coefficients of the ordered logit regression generate a surface that describes the probability of a transition in broom snakeweed biomass, given the effects of exogenous weather and precipitation, grazeable forage availability, and snakeweed density (Table 3).

\section{Economic Data}

Prices for stockers in the model are estimated as moving average MA(1) processes for both stocker purchase prices and stocker sale prices. These prices are based on observed annual stocker prices from 1976 to 2014. Stocker purchase and sale prices change annually, based on the supply of cattle available in the market and the demand for cattle within that year. The stocker purchase prices are expressed in dollars per $\mathrm{kg}$, and are modeled using a MA(1) process with a mean of 3.7097, a volatility parameter of 0.58092 , and a moving average coefficient of 0.58509 . These prices are modeled to follow the inter-annual fluctuation observed in purchase prices. Because stocker sale prices are lower on a per-kg basis (because end-season cattle are heavier in total), we model stocker sales prices as a discount on the 
Table 2. Summary Statistics for Data Used in Determination of Broom Snakeweed Transition Probabilities

\begin{tabular}{lrrrrr}
\hline & \multicolumn{2}{c}{ Baseline } & & \multicolumn{2}{c}{ RCP 8.5 } \\
\cline { 2 - 3 } \cline { 5 - 6 } & Average & $\begin{array}{c}\text { Standard } \\
\text { Deviation }\end{array}$ & & Average & $\begin{array}{l}\text { Standard } \\
\text { Deviation }\end{array}$ \\
\hline Quarter 2 Precipitation & 18.36 & 9.772 & & 11.7 & 6.52 \\
Quarter 3 Precipitation & 9.91 & 5.654 & & 4.77 & 3.068 \\
April Temperature & 15.36 & 1.476 & & 20.19 & 1.611 \\
June Temperature & 25.16 & 1.273 & & 31.63 & 1.988 \\
\hline
\end{tabular}

purchase price that follows an MA(1) process with a mean of -0.7206 , a volatility parameter of 0.33924 and a moving average coefficient of 0.017559 .

Cost and return budgets for a 200-head stocker operation from (Eborn, Harrison, and Rimbey 2016) were used as the basis for the per-head variable costs. These variable costs include two weeks of alfalfa hay (before the steers are placed on the range), salt, marketing, hauling, pasture charges, interest on operating capital, and veterinary services. All of the prices and costs in the model are expressed in 2015 dollars and are deflated using the Producer Price Index (PPI).

\section{Results}

\section{Broom Snakeweed Biomass Transition Probability}

Fitted parameters from Torell et al. (2018) (Table 3) are used to create a surface of estimated probabilities for broom snakeweed biomass and then generate point probabilities of site transition to heavier or lighter broom snakeweed invasion, given the exogenous weather outcomes and the amount of standing forage in the site. Figure 2 illustrates a surface of transition probabilities from light broom snakeweed invasion to heavy invasion as a function of both broom snakeweed and forage production in the previous time period. Generally, the probability of transition to the heavy state of invasion is highest when blue grama production in the previous period was low and broom snakeweed density was high. When blue grama production or broom snakeweed production at a site is low, the probability that the site will transition to heavier broom snakeweed invasion is also low.

\section{Vegetation Transition Simulations}

As a demonstration of the differences in probabilities of vegetation transition under the two climate scenarios, consider the case where all explanatory 
Table 3. Ordered Logit Regression Results, as Computed in Torell (2018)

\begin{tabular}{lclrc}
\hline Variable Name & Coefficient & Std. Err. & \multicolumn{1}{c}{$\boldsymbol{Z}$} & $\boldsymbol{P}>\boldsymbol{z} \mid$ \\
\hline Snakeweed Standing Crop & -0.001652 & 0.00075 & -2.20 & 0.028 \\
Snakeweed Density & -0.112171 & 0.0454337 & -2.47 & 0.014 \\
Forage Density & 0.002471 & 0.0011576 & 2.13 & 0.033 \\
Temp April & -0.37569 & 0.1563173 & -2.40 & 0.004 \\
Temp June & 0.546756 & 0.1923828 & 2.84 & 0.036 \\
Q2 Rainfall & -0.091555 & 0.0435851 & -2.10 & $<0.0001$ \\
Ancillary Variables & & & & \\
$\quad$ Cut 1 $\left(k_{1}\right)$ & 4.682365 & 3.603575 & & \\
$\quad$ Cut 2 $\left(k_{2}\right)$ & 6.861632 & 3.625637 & & \\
$\quad$ Cut 3 $\left(k_{3}\right)$ & 8.406076 & 3.654405 & & \\
Fit Statistics & & & & \\
$\quad$ Log likelihood & -80.4350 & & & \\
$\quad N$ & 105 & & & \\
$\quad$ Likelihood test, LR $\chi^{2}(7)$ & 119.34 & & & \\
$\quad$ Pseudo $R^{2}$ & 0.4259 & & & \\
\hline
\end{tabular}

variables are set at the population average for each climate scenario. The ordered logit model estimates that under the baseline climate conditions, it is most likely that the plot will either remain in its current state of invasion or transition to a more heavily invaded state (Figure 3a). Under the RCP 8.5 scenario, the probabilities of transition to any other state (lower or higher) of invasion are more variable (Figure $3 b$ ).

Under the baseline climate scenario (Figure 3a), if the starting state of broom snakeweed invasion is "none" (the first row of boxes), the estimated probability that the next period's invasion levels will remain at "none" is 30 percent. The estimated probability that the site transitions to "light" broom snakeweed infestation is 37 percent; to "moderate" infestation, 28 percent; and to "heavy" infestation, 5 percent. In the baseline climate scenario, when broom snakeweed started in a "heavy" invasion state, the probability of remaining in "heavy" invasion state is estimated to be 96 percent. By contrast, in the RCP 8.5 scenario, the probability of remaining in lower, transitioning to lower or highest states of invasion dominate. For example, if the starting state of invasion is "none," the probability of remaining at "none" is 47 percent and the probability of transitioning to "light" is 24 percent, "moderate" is 11 percent, and "heavy" is 17 percent. If the plot is in the invasion state "heavy," the probability of remaining in "heavy" is 22 percent, and there is an estimated 58 percent probability that plots with "heavy" broom snakeweed invasion will transition to a "light" infestation state. 


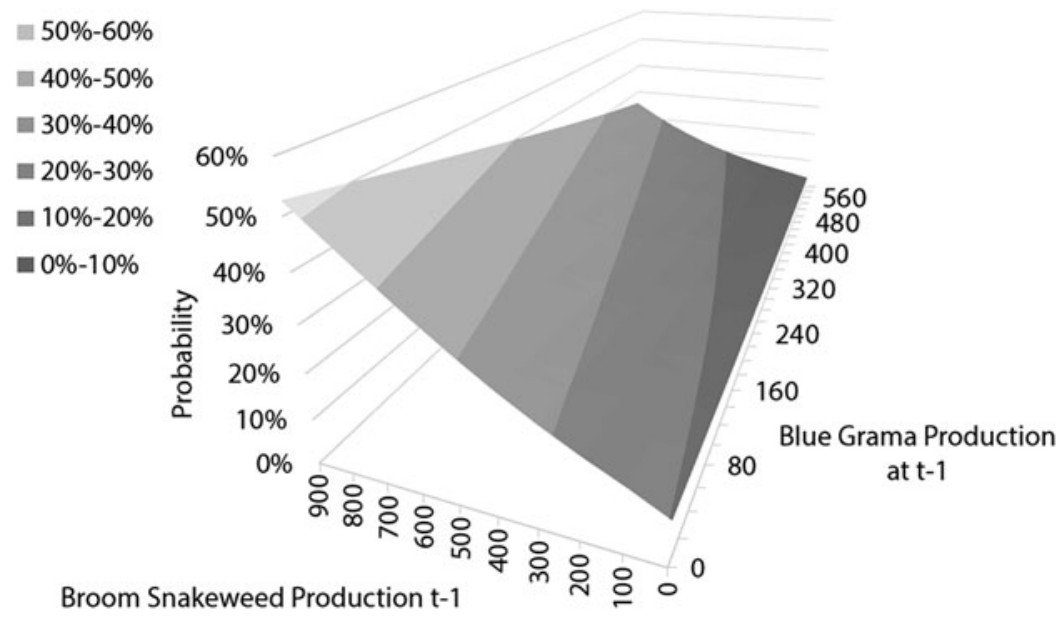

Figure 2. Probabilities of rangeland sites transitioning to a heavy state of snakeweed invasion, as a function of snakeweed and forage density in the previous period. Forage density is also a function of the previous period stocking rate.

Overall, under RCP 8.5, the probabilities of transitioning to the extremes, invasion states "heavy" and "none" dominate in comparison to the baseline scenario. Under the RCP 8.5 scenario, the probability of transition to a different state of broom snakeweed invasion becomes more likely. Notably, the direction of change under the RCP 8.5 scenario trends toward lesser invaded states, and considering multiple time periods, may lead to an eventual transition to "none." One important caveat to this finding is an increased probability of transition to "heavy" invasion state; while broom snakeweed may be less tolerant of conditions created by climate change in the desert Southwest in the long run, there may be a short run transition to "heavy" infestation before transitioning to an invasion state of "light" or "none."

\section{Estimated Distributions of Blue Grama and Broom Snakeweed Production}

Figure 4 shows the estimated probability density functions of the simulated grazeable forage biomass using profit maximizing and 50 percent utilization stocking rules for the baseline and RCP 8.5 scenarios. Epanechnikov kernel density estimations were used to create the estimated probability density functions. These data are the result of previous stocking rates and random weather draws influencing the level of blue grama production and broom snakeweed invasion in that period.

We performed Kolgomorov-Smirnov tests to determine if the distributions for all variables generated by the two grazing rules were significantly different. 
A. Baseline
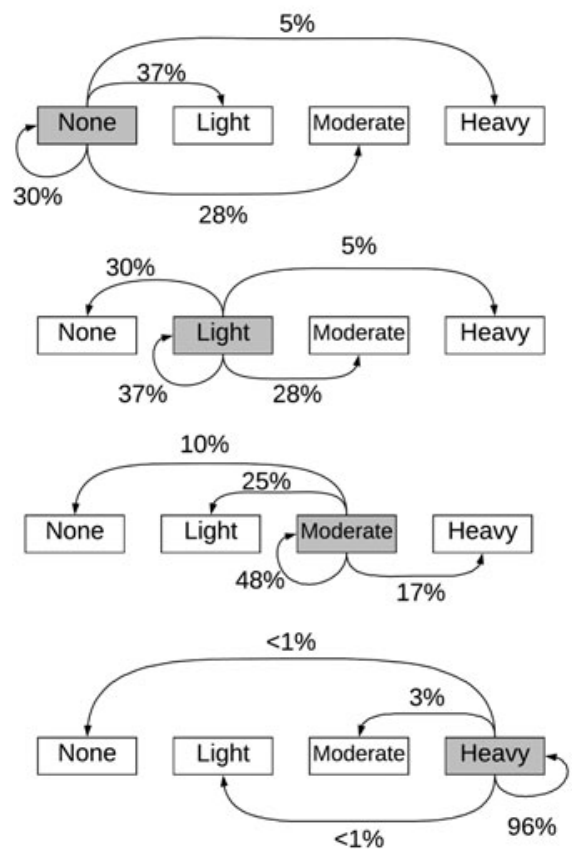

B. RCP 8.5
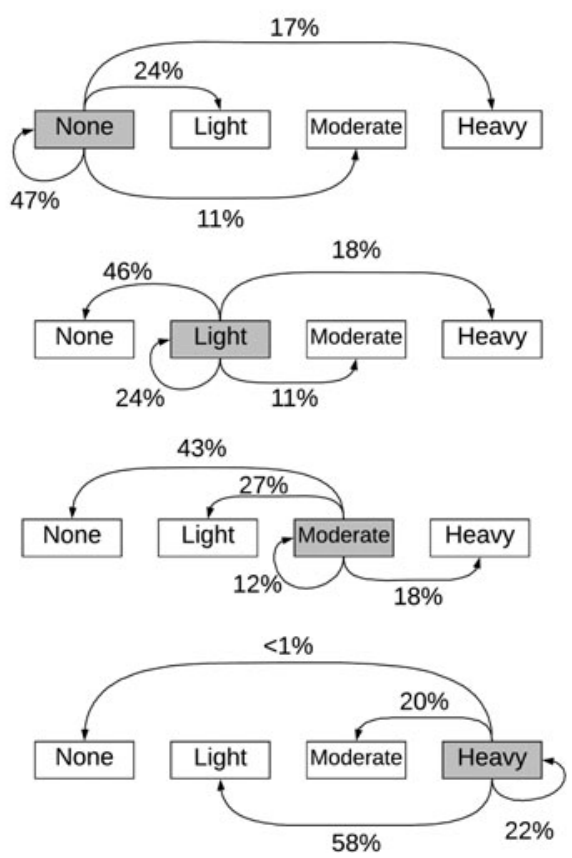

Figure 3. Transition probabilities from each state of broom snakeweed invasion to alternative states for the baseline (a) and RCP 8.5 greenhouse gas concentrations (b). Boxes shaded grey illustrate the existing invasion state of the site and arrows to other boxes depict transition to other states of invasion.

Though the distributions are statistically different from each other, when comparing forage outcomes using profit maximizing and 50 percent utilization rules for setting stocking rates within each climate scenario, the difference in forage production between use of the two rules is not biologically significant (Figure $4 \mathrm{a}$ and b). Similarly, there is little difference in standard deviation. In general, the 50 percent utilization rule produces more grazeable forage on average because the rule results in setting more conservative stocking rates. However, the average additional forage produced under 50 percent utilization amounts to roughly 8 kilograms per hectare, a difference that would require more than 45 hectares of land to support the forage requirements of one additional steer.

Comparing across climate scenarios, the difference is much more dramatic. Under RCP 8.5, production of little to no grazeable forage occurs more frequently, average forage production is lower, and the maximum forage production is considerably lower than in the baseline scenario (Figure $4 \mathrm{~b}$ ). 

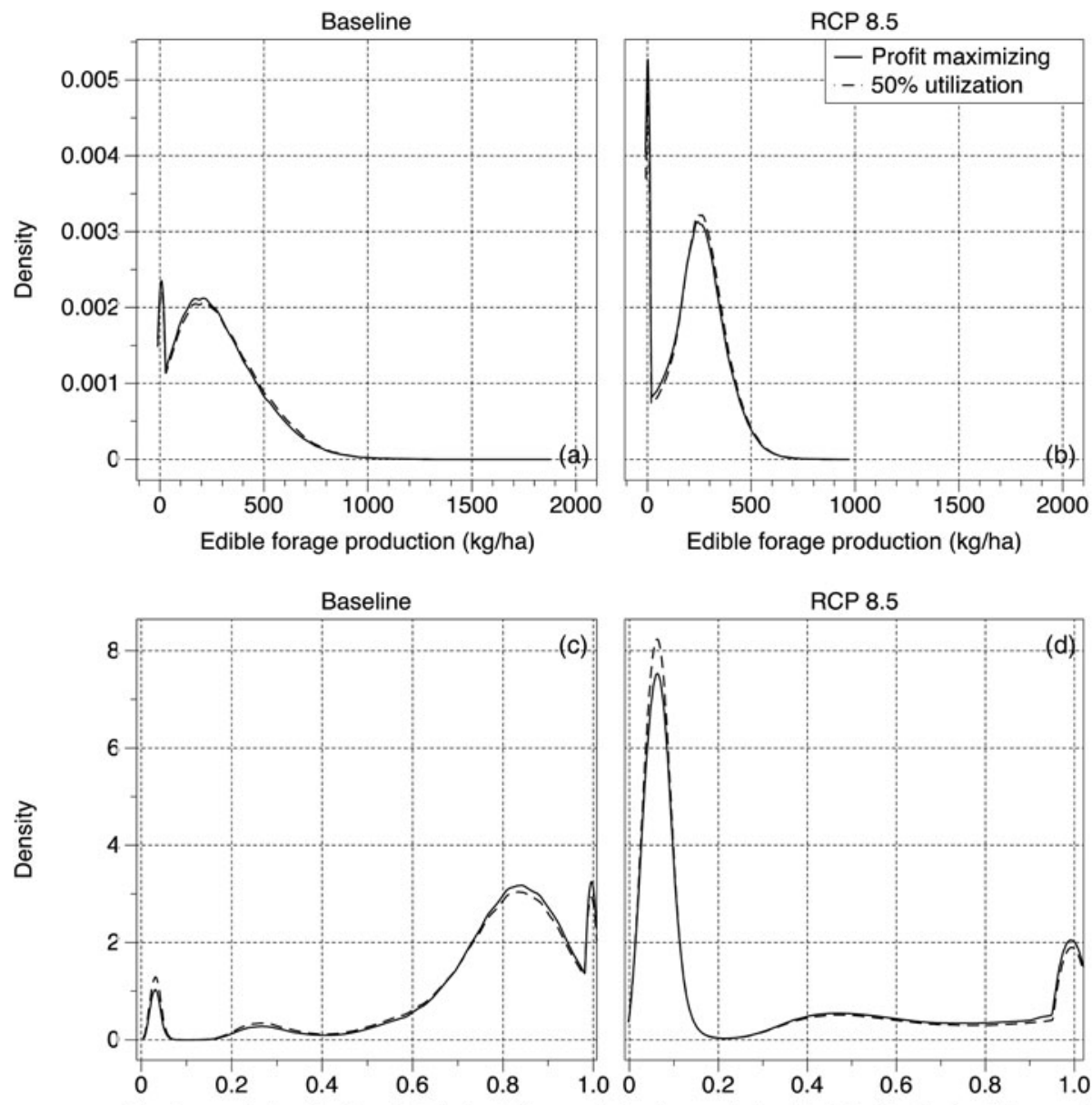

Snakeweed density (\% of total plant biomass) Snakeweed density (\% of total plant biomass)

Figure 4. Kernel density estimates of (a) simulated grazeable forage production under the baseline greenhouse gas scenario; (b) grazeable forage production under the RCP 8.5 greenhouse gas scenario, (c) broom snakeweed density as a percentage of total plant biomass under the baseline scenario; (d) broom snakeweed density under RCP 8.5 scenario. Kernel density estimates for both stocking rules, profit maximizing and $\mathbf{5 0}$ percent utilization are shown.

For example, under the profit-maximizing grazing rule, average forage production in the baseline case is 276.1 kilograms per hectare, while in the RCP 8.5 case, average forage production falls to 224.9 kilograms per hectare, a statistically significant difference of 51 kilograms per hectare. The shift in the distribution of outcomes under RCP 8.5 conditions represents a reduction of the likelihood of years with high forage production. 
Figure 4c and d shows estimated probability density functions of simulated broom snakeweed production. Snakeweed density is measured as a percentage of total plant material produced at a site. Comparing outcomes between grazing rules, while Kolmogorov-Smirnov tests indicate a statistically significant difference between distributions, there is little economic or ecological difference between broom snakeweed density using profit maximizing and 50 percent utilization. The difference in overall broom snakeweed density across climate scenarios is quite striking. Under the baseline climate scenario (Figure 4c), the average level of broom snakeweed invasion is high, with more than 75 percent of the total plant material produced on the range being broom snakeweed. By contrast, the average level of broom snakeweed invasion falls dramatically under the RCP 8.5 climate conditions, to an average invasion level of 33 percent (Figure 4d).

The outcomes for grazeable forage production and broom snakeweed production, as well as the probabilities of transition show several challenging factors for grazing management and for land management more generally. Broom snakeweed invasion does decrease on average under the RCP 8.5 scenario. However, the reduction in broom snakeweed density occurs with a coincident fall in grazeable forage production, which in turn decreases allowable stocking rate.

\section{Estimated Distributions of Seasonal Stocking Rate and Net Present Value}

Estimated probability density functions of the simulated stocking rates are shown in Figure 5. Across both climate scenarios, stocking rates tend to be higher under the profit-maximizing grazing rule, consistent with economic theory. Under the RCP 8.5 climate scenario, both stocking rates are overall lower than under the baseline climate scenario. Lower stocking rates under both profit maximizing and 50 percent utilization rules are a result of the impact of climate change on forage production - an increase in the number of low production years and therefore the number years that the land cannot support cattle. The average stocking rate in the baseline climate scenario under the profit-maximizing grazing rule is 0.10 steers per hectare per year, compared to 0.08 steers per hectare per year in the RCP 8.5 scenario. Using the 50 percent utilization rule, the average stocking rate in the baseline climate scenario is 0.06 steers per hectare, which falls to 0.05 steers per hectare under the RCP 8.5 climate conditions. The conditions created by the RCP 8.5 projections increase the number of years in which stocking rates fall to zero or near zero. During these years, the economical decision would be to destock the range. Under the baseline climate conditions, 11.54 percent of years have stocking rates below 0.0001 steers per hectare, while 15.3 percent of years have these low stocking rates in the RCP 8.5 climate conditions. As many as 16.3 percent of years have near zero stocking rates in the RCP 8.5 scenario under profit-maximizing grazing. These results indicate that rangeland profitability is likely to fall as climate change impacts begin to 

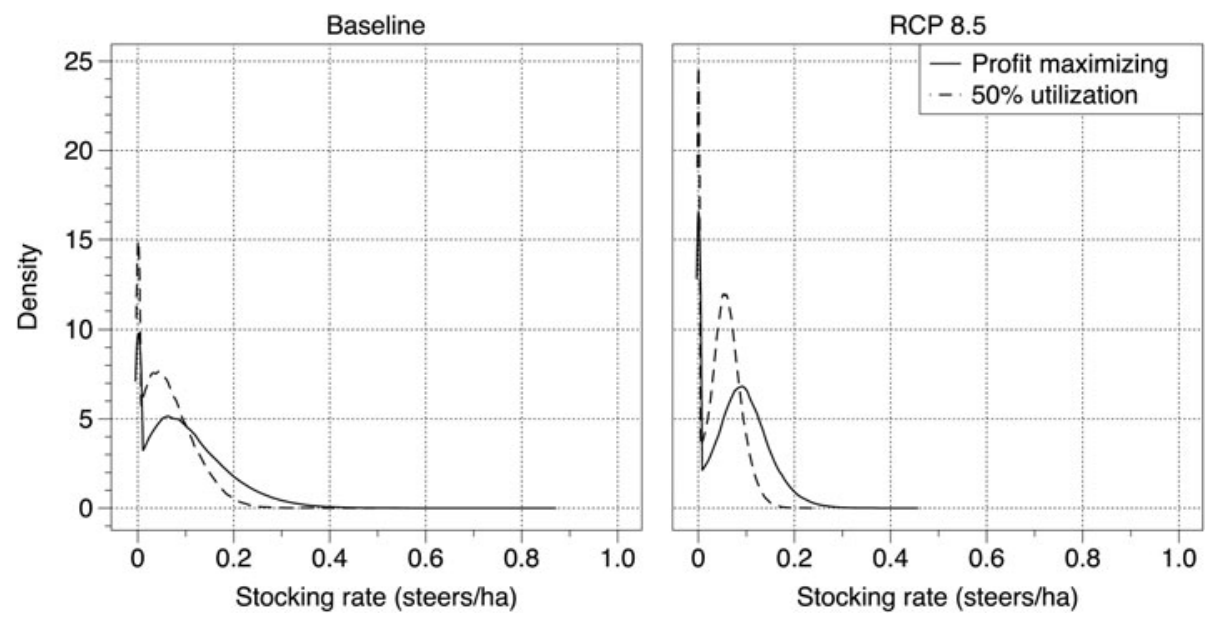

Figure 5. Kernel density estimates of the chosen stocking rates (steers per hectare) under profit maximizing and 50 percent utilization rules for the baseline and RCP 8.5 climate scenarios.

occur, meaning that managers will find it increasingly difficult to justify remaining in business without major changes in management and adaptation strategies.

The standard deviation of outcomes decreases under the RCP 8.5 climate scenario, with the standard deviation of stocking rates falling from 0.08 steers per hectare to 0.06 under the profit-maximizing grazing rule, and from 0.05 steers per hectare to 0.03 under 50 percent utilization rule. This reduction in standard deviations reflects the decreased number of years with high forage production as compared to the baseline climate conditions.

Net present values are calculated as the discounted sum of net revenue on a per hectare basis over the 20-year time horizon using a 4 percent discount rate. Estimated probability density functions of the simulated net present values for each stocking rule and climate scenario are shown in Figure 6. Comparing the outcomes produced by the two stocking rules, the profit-maximizing stocking rule significantly outperforms 50 percent utilization. This outcome occurs because under a 50 percent utilization framework the grazing manager always chooses a stocking rate that consumes half of the available forage, no matter the observed level of forage. In contrast, the profit-maximizing stocking rates take advantage of periods of high forage production by opting for stocking rates above 50 percent utilization. For the baseline climate scenario, the average net present value is $\$ 347.42$ per hectare using a profitmaximizing stocking rule. The average net present value falls to $\$ 283.93$ under the 50 percent utilization rule, a statistically significant difference of $\$ 63.49$ per hectare. 

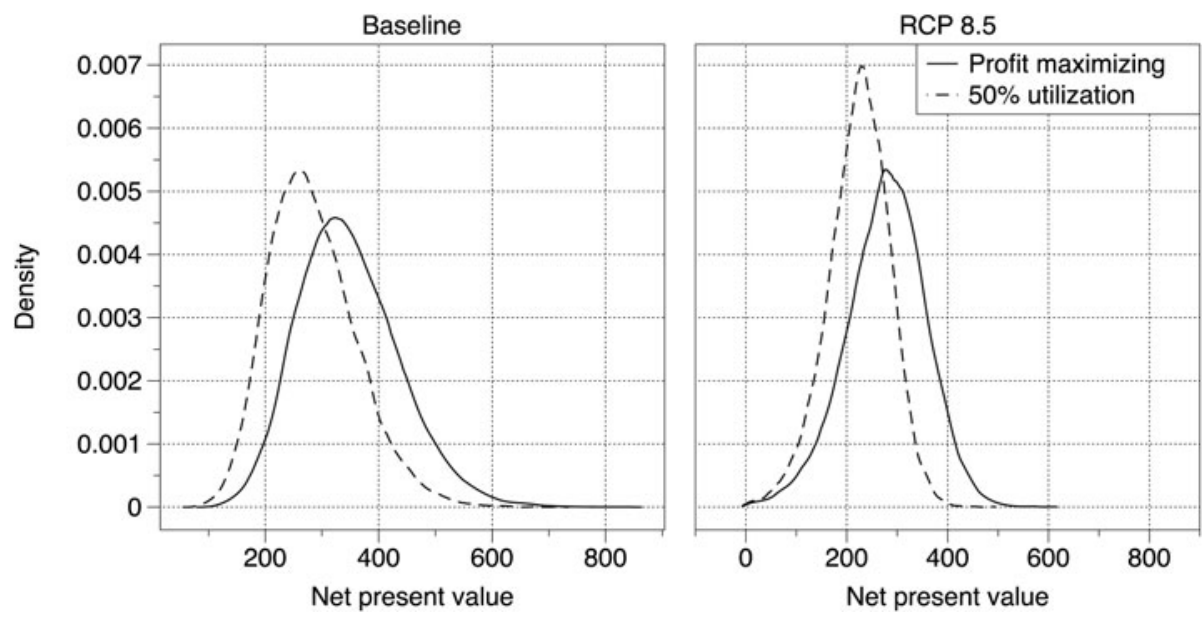

Figure 6. Kernel density estimates of the net present value of rangeland livestock production under profit maximizing and 50 percent utilization rules for the baseline and RCP 8.5 climate scenarios.

Comparing across climate scenarios, the difference is more dramatic. Using the profit-maximizing stocking rule, the average net present value in the baseline climate scenario is $\$ 347.42$ per hectare as before, which falls to $\$ 277.48$ per hectare in the RCP 8.5 scenario, a statistically significant difference of $\$ 69.94$ per hectare. Similar to forage production, the standard deviation of net present values falls in the RCP 8.5 scenario from $\$ 89.67$ to $\$ 75.79$.

Comparing the moments of each stocking rule in the RCP 8.5 scenario to the baseline outcome is useful in understanding the impacts of climate change on rangeland systems. First, the means of both RCP 8.5 distributions are shifted to the left. This shift indicates that years of low-to-moderate returns to become more likely, the lowest observed net present values to fall to zero, and the high returns that were possible under baseline climate conditions become unattainable. In addition, the RCP 8.5 scenario reduces the standard deviation of net present values for both grazing rules, with the standard deviation of NPV falling to $\$ 61.80$ from $\$ 77.99$ for the 50 percent utilization rule and to $\$ 78.81$ from $\$ 89.36$ for the profit-maximizing stocking rate rule.

Compared to the baseline climate conditions, the conditions assumed in the RCP 8.5 climate scenario will have negative effects on rangeland conditions. Under the baseline conditions, the estimated probabilities of a site remaining in the same state or transitioning to a higher state of broom snakeweed invasion are highest. In the RCP 8.5 outcome, the transition to any other state of broom snakeweed invasion is more variable and unpredictable. Production of both grazeable forage and broom snakeweed are both projected to 
decrease. The effect of climate change on forage and snakeweed production translates into a decrease in viable stocking rates as well as the economic value of the range for livestock producers.

\section{Conclusions and Implications}

This paper quantifies the impacts of climate change projections, namely temperature and precipitation, on range ecology and economic outcomes resulting from use of a commonly used stocking rule. Our approach complements existing work that predicts the ecological impacts of climate change on rangelands (Baker et al. 1993; McCollum et al. 2017 and others) and the rangeland economics and management literature that has explored stocking recommendations under climatic uncertainty (Ritten et al. 2010; Kachergis et al. 2014; Kobayashi, Rollins, and Taylor 2014).

While existing work has considered the impacts of temperature and precipitation stochasticity on forage production, we also consider the impacts of climate on noxious weed biomass, where the weed competes with native vegetation. We then use ecological outcomes to inform the determination of stocking rates and ranch productivity. Our estimates and simulations suggest that the greater atmospheric greenhouse gas concentrations become, the greater the probability of transition to very high, low (or no) invasion density. Moreover, higher concentrations of greenhouse gases reduce the capacity of rangelands to provision livestock grazing. This work informs both prioritization of management objectives and continued use of stocking rules of thumb.

What are the implications of these findings for management and policy makers? Managers face an exhaustive list of constraints in sustaining rangelands, including budget fluctuations, fire seasons, and uncertainty surrounding invasive species introductions, weed control, and habitat restoration. These uncertainties and constraints require prioritization of actions based on the likelihood investments will produce benefits. Controlling or removing broom snakeweed has been a management objective in Southwestern rangelands for nearly a century. Under existing climate conditions, if left unmanaged, habitat will transition to higher densities of broom snakeweed with almost certainty. However, under a scenario of high future atmospheric greenhouse gas concentrations, the transition probabilities estimated in this work indicate that if left unmanaged, broom snakeweed density in the Southwest may decrease in the long run. However, there is also an increased probability of transition to the invasion state "heavy," These results for future rangeland conditions and their economic implications can assist managers in prioritizing allocation of their limited resources.

Second, our results indicate that managers must proceed with caution when using of stocking rules of thumb under increasing climate volatility. The 50 percent utilization rule is widely used because it is simpler to implement than an economic model and its outcomes have historically approximated a profitmaximizing rule. Under a future high greenhouse gas scenario, however, the 50 
percent utilization rule results in consistently lower levels of available forage, stocking rates, and ranch-level profitability. If commonly practiced stocking rules fail to perform under likely future scenarios in the future, the current time is an opportunity to solidify transition from historically valid management rules to an adaptive management approach, allowing for more flexibility in changing decisions within and between seasons. A logical extension to this work would be to develop an optimal control model to incorporate stochastic weather patterns and a foresighted decision-making framework. A more complete extension of this work would include the work of ecologists to better understand plant responses to changing climate conditions, particularly interspecies competition between forage and invasive species.

Broom snakeweed is just one of many potential risks to rangeland ecosystems affected by climate change. The results of this paper indicate the need for a greater understanding of the linkages between ecological and economic outcomes by putting long-term ecological data to use in economic and management frameworks. Integrating ecological realism through state-andtransition models is an area of active research in the rangeland economics field; development in conjunction with a focus on climate change impacts should be an area for the future. This analysis has shown that the way of life that rangelands support may be at risk, and that the continued incorporation of ecology and economics is a critical need.

\section{Acknowledgements}

This work is supported by the USDA National Institute of Food and Agriculture Hatch Project Number 1012756 and USDA National Institute of Food and Agriculture Hatch Project Number 1012856. We thank the participants of the Northeast Agricultural and Resource Economics Association Post-Meeting Workshop and two anonymous reviewers for helpful suggestions. The views expressed are the authors' and do not necessarily represent the policies or views of any sponsoring agencies.

\section{References}

Baker, B.B., J.D. Hanson, R.M. Bourdon, and J.B. Eckert. 1993. "The Potential Effects of Climate Change on Ecosystem Processes and Cattle Production on U.S. Rangelands." Climatic Change 25(2): 97-117.

Briske, D.D., L.A. Joyce, H.W. Polley, J.R. Brown, K. Wolter, J.A. Morgan, B.A. McCarl, and D.W. Bailey. 2015. "Climate-change Adaptation on Rangelands: Linking Regional Exposure with Diverse Adaptive Capacity." Frontiers in Ecology and the Environment 13(5): 249-256.

Costanza, R., R. d'Arge, R. de Groot, S. Farber, M. Grasso, B. Hannon, K. Limburg, S. Naeem, R.V. O'Neill, J. Paruelo, R.G. Raskin, P. Sutton, and M. van den Belt. 1997. "The Value of the World's Ecosystem Services and Natural Capital." Nature 387(6630): 253-260.

Eborn, B., S. Harrison, and N. Rimbey. 2016. "2016 Costs and Returns Estimate. Stocker Budget: 200-head No Wintering Bought in Spring \& Sold in Fall." No. EBB-ST3-16, University of Idaho Extension. 
Gent, P.R., G. Danabasoglu, L.J. Donner, M.M. Holland, E.C. Hunke, S.R. Jayne, D.M. Lawrence, R. B. Neale, P.J. Rasch, M. Vertenstein, P.H. Worley, Z.-L. Yang, and M. Zhang. 2011. "The Community Climate System Model Version 4." Journal of Climate 24(19): 4973-4991.

Hart, R. H., M.J. Samuel, P.S. Test, and M.A. Smith. (1988). “Cattle, Vegetation, and Economic Responses to Grazing Systems and Grazing Pressure." Journal of Range Management, 41 (4): 282-286.

Havstad, K., D. Peters, B. Allen-Diaz, J. Bartolome, B. Bestelmeyer, D. Briske, J. Brown, M. Brunson, J. Herrick, L. Huntsinger, P. Johnson, L. Joyce, R. Pieper, T. Svejcar, and J. Yao. 2009. "The Western United States Rangelands: A Major Resource." In Grassland Quietness and Strength for A New American Agriculture. Madison, WI: American Society of Agronomy, Crop Science Society of America, Soil Science Society of America, 75-93. Available at https://doi.org/10.2134/2009.grassland.c5.

Havstad, K.M., D.P.C. Peters, R. Skaggs, J. Brown, B. Bestelmeyer, E. Fredrickson, J. Herrick, and J. Wright. 2007. "Ecological Services to and From Rangelands of the United States." Ecological Economics 64(2): 261-268.

Kachergis, E., J.D. Derner, B.B. Cutts, L.M. Roche, V.T. Eviner, M.N. Lubell, and K.W. Tate. 2014. "Increasing Flexibility in Rangeland Management During Drought." Ecosphere 5(6): 1-14.

Kobayashi, M., K. Rollins, and M.H. Taylor. 2014. "Optimal Livestock Management on Sagebrush Rangeland with Ecological Thresholds, Wildfire, and Invasive Plants." Land Economics 90(4): 623-648.

McCarthy, N., E. Sadoulet, and A. de Janvry. 2001. “Common Pool Resource Appropriation Under Costly Cooperation." Journal of Environmental Economics and Management 42 (3): 297-309.

McCollum, D.W., J.A. Tanaka, J.A. Morgan, J.E. Mitchell, W.E. Fox, K.A. Maczko, L. Hidinger, C.S. Duke, and U.P. Kreuter. 2017. "Climate Change Effects on Rangelands and Rangeland Management: Affirming the Need for Monitoring." Ecosystem Health and Sustainability 3(3): e01264. Available at https://doi.org/10.1002/ehs2.1264

McDaniel, K.C. 1984. "Broom snakeweed control with herbicides." Agricultural Experiment Station Bull. No. 706, New Mexico State University.

McDaniel, K.C., L.A. Torell, and J.W. Bain. 1993. "Overstory-Understory Relationships for Broom Snakeweed-Blue Grama Grasslands." Journal of Range Management 46(6): 506511.

Moss, R.H., J.A. Edmonds, K.A. Hibbard, M.R. Manning, S.K. Rose, D.P. van Vuuren, T.R. Carter, S. Emori, M. Kainuma, T. Kram, G.A. Meehl, J.F.B. Mitchell, N. Nakicenovic, K. Riahi, S.J. Smith, R. J. Stouffer, A.M. Thomson, J.P. Weyant \& T.J. Wilbanks. 2010. "The Next Generation of Scenarios for Climate Change Research and Assessment." Nature 463: 747-756.

Nicol, S., R.A. Fuller, T. Iwamura, and I. Chades. (2015). "Adapting Environmental Management to Uncertain But Inevitable Change." Proceedings of the Royal Society of London B, 282 (1808): 20142984.

Pachauri, R.K., and A. Reisinger. 2007. “Climate Change 2007 Synthesis Report: Summary for Policymakers." IPCC Secretariat.

Quaas, M.F., S. Baumgärtner, C. Becker, K. Frank, and B. Müller. 2007. "Uncertainty and Sustainability in the Management of Rangelands." Ecological Economics 62(2): 251-266.

Reeves, J.L., J.D. Derner, M.A. Sanderson, M.K. Petersen, L.T. Vermeire, J.R. Hendrickson, and S. L. Kronberg. 2013. "Temperature and Precipitation Affect Steer Weight Gains Differentially by Stocking Rate in Northern Mixed-Grass Prairie." Rangeland Ecology \& Management 66(4): 438-444.

Ritten, J.P., W.M. Frasier, C.T. Bastian, and S.T. Gray. 2010. "Optimal Rangeland Stocking Decisions under Stochastic and Climate-Impacted Weather." American Journal of Agricultural Economics 92(4): 1242-1255.

Torell, L.A., K.S. Lyon, and E.B. Godfrey. 1991. "Long-Run versus Short-Run Planning Horizons and the Rangeland Stocking Rate Decision." American Journal of Agricultural Economics 73(3): 795-807. 
Torell, L.A., K.C. McDaniel, J.R. Brown, and G.L. Torell. 2018. "Broom Snakeweed (Gutierrezia sarothrae) Population Change in Central New Mexico: Implications for Management and Control." Rangeland Ecology \& Management 71(2): 228-238. Available at http://www. sciencedirect.com/science/article/pii/S1550742417301094 (Accessed February 2, 2018).

Ueckert, D.N. 1979. "Broom Snakeweed: Effect on Shortgrass Forage Production and Soil Water Depletion." Journal of Range Management 32(3): 216-220. 